\section{P180 IMPACT OF THE LONDON LOW EMISSION ZONE ON CHILDREN'S RESPIRATORY HEALTH: A SEQUENTIAL YEARLY CROSS SECTIONAL STUDY 2008-2014}

${ }^{1} \mathrm{CJ}$ Griffiths, ${ }^{2}$ I Mudway, ${ }^{2} \mathrm{H}$ Wood, ${ }^{1} \mathrm{~N}$ Marlin, ${ }^{1} \mathrm{I}$ Dundas, ${ }^{1} \mathrm{R}$ Walton, ${ }^{1} \mathrm{G}$ Grigg, ${ }^{3} \mathrm{~A}$ Sheikh, ${ }^{4} \mathrm{~T}$ Lee, ${ }^{2} \mathrm{~F}$ Kelly. ${ }^{1}$ Asthma UK Centre for Applied Research, Queen Mary University of London, London, UK; ${ }^{2}$ MRC PHE Centre for Environment and Health, Kings College London, London, UK; ${ }^{3}$ Asthma UK Centre for Applied Research, Edinburgh University, Edinburgh, UK; ${ }^{4}$ MRC Asthma UK Centre in Allergic Mechanisms of Asthma, Kings College London, London, UK

\subsection{6/thoraxjnl-2016-209333.323}

Background Low Emission Zones are a novel public health intervention to address the adverse effects of traffic pollution on health. We investigated the association between traffic derived air pollutants and lung function in 8-9 year old children living in London's Low Emission Zone.

Methods Sequential yearly cross-sectional study of 2,297 children aged 8-9 years attending east London primary schools between 2009 and 2014, following the introduction of the Low Emission Zone. We examined the relationship between pollutant exposures (NOx, NO2, PM2.5 and PM10) and lung function. We assigned annual exposures by each child's residential address. In addition, we used spatially resolved estimates of 12-hour, 24-hour, 7-day and annual exposures prior to each child's assessment, allowing us to compare the relative effects of very short-, short-, mediumand long-term pollutant exposures. Primary outcome measure was post-bronchodilator FEV1.

Findings We found inverse associations between exposures of PM10 and PM2.5 in the week prior to children's assessment and FEV1 ( $\mathrm{P}<0.05)$; and inverse associations between annual exposures of PM10, NOx, and NO2, and FVC ( $1<0.05)$; and exposures of PM10 and PM2.5 in the week prior to assessment, and FVC $(\mathrm{p}<0.05)$. No associations were seen when shorter term exposure estimates were employed. We found no evidence of improvements in lung function over the duration of the Low Emission Zone.

Interpretation Exposure of children to traffic pollution in central London is associated with decreased lung function and lung volumes. No detectable health benefit followed the introduction of the Low Emission Zone.

\section{\begin{tabular}{|l|l}
\hline P181 TRANSITION ARRANGEMENTS FOR YOUNG ADULTS \\
\hline
\end{tabular} WITH ASTHMA: UK NATIONAL SURVEY}

CWJ Lee, BR Patel, T Nagarajan, H James, H Burhan, GH Jones. Royal Liverpool University Hospital, Liverpool, UK

\subsection{6/thoraxjnl-2016-209333.324}

Introduction Transition of young adults (YA) from specialist paediatric to adult services is an active process that requires specific management and planning and does not merely represent the transfer of care as a single event. In other chronic diseases (e. g. Cystic Fibrosis; T1DM) it is well acknowledged that clinical outcomes improve when this process is well organised and where this is lacking the risk of non-adherence to treatment and loss of disease control increases. BTS guidelines ${ }^{1}$ clearly recommend a coordinated approach when transitioning YA in an asthma setting. Despite the importance of this process, little information is available on transition arrangements in asthma services.

Methods An online survey was sent to 105 trusts with adult asthma services in all parts of the UK to establish their transition arrangements.
Results Of the 43 responding centres (District General Hospital $\mathrm{n}=20$ ), only $60 \%$ had a designated lead $(\mathrm{n}=26)$ and less than half made any form of specific arrangements for transition $(\mathrm{n}=18)$. University Hospital trusts were more likely to have transitional care arrangements in place $(\mathrm{n}=11 / 22)$ than District General Hospitals $(n=6 / 20)$. In those centres that did run joint clinics $(\mathrm{n}=16)$, in the majority of cases this only involved adult team members attending paediatric clinics $(n=10)$.

Most centres $(n=25)$ expected $\leq 5$ patients to transition each year and over $90 \%(\mathrm{n}=37)$ did not initiate contact with YA until they were $\geq 15$ yrs old. Only a third of centres delayed transition if YA were not perceived to be ready $(n=15)$ or remained in full time education $(\mathrm{n}=15)$.

Overall less than a third of respondents $(n=13)$ were satisfied with their transition arrangements.

Conclusions Our survey reveals for the first time the wide variation in approaches to transition in asthma clinics across the UK. Our data suggests that currently most centres are not committing the recommended resources towards this process, no doubt hampered in part by the relatively small numbers of young adults with asthma transitioning each year.

\section{REFERENCE}

1 British Thoracic Society. BTS/SIGN Asthma guideline. 2014. https://www.brit-thoracic.org.uk/document-library/clinical-information/asthma/btssign-asthma-guideline2014/ (accessed 28 June 2016)

\section{P182 CURRENT CHARACTERISTICS, COPING STRATEGIES AND OUTCOMES OF YOUNG PEOPLE WITH CYSTIC FIBROSIS TRANSITIONING TO ADULTHOOD}

R Miller, K Askew, J Bamford, N Hudson, J Moratelli, A Anderson, S Doe, SJ Bourke. Royal Victoria Infirmary, Newcastle upon Tyne, UK

\subsection{6/thoraxjnl-2016-209333.325}

Introduction Transition is a process that addresses the medical, psychosocial and vocational needs of young adults, and it is a crucial stage for patients with CF.

Methods Patients who transferred to the adult service via a transition clinic within the last 5 years underwent an interview with a psychologist using a questionnaire of demographic data, their experience of transition, their concerns and the effect of CF on their lifestyle. They completed the Hospital Anxiety Depression Scale (HADS) and the Ways of Coping Scale. Clinical data, complications and outcomes were noted at transfer and one year later.

Results 45 patients $(27$ men) participated; mean age at transfer was 17 (range 15-21) years and at interview was 20.7 (17-24) years; 25 (53\%) had chronic Pseudomonas infection, 7 (15.5\%) were receiving gastrostomy feeding, 9 had diabetes, one had had liver transplantation and one had undergone termination of pregnancy. At the transition clinic 94\% attended with a parent but after transfer $33 \%$ attended alone and $18 \%$ with a partner; $87 \%$ felt that the timing of transition was correct and $80 \%$ found the transition clinic helpful. Self-reported adherence to treatment declined in $18 \%$ and improved in $24 \%$. Life satisfaction was high with $74 \%$ reporting that $\mathrm{CF}$ had no effect on their social lives, but $52 \%$ felt it impacted on work or studies, although $76 \%$ were in employment or education. Mean FEV1 remained stable at $76.6(26.4-119.6) \%$ at transfer and $75.4(19-111) \%$ one year later, but varied with 15 patients (33\%) having a deterioration of $>5 \%$ and $8(18 \%)$ improving by $>5 \%$. Mean BMI changed from $20.8(16.5-29.7)$ to $21.2(17.3-29.2) ; 11$ patients $(24 \%)$ 